\title{
Effect of Fatty Acids ( Myristic and Palmatic Acids ) on the Rheological Properties and Swelling Power of Sago Starch
}

\author{
Noha M. Yahya \\ Department of Pharmaceutical Science \\ College of Pharmacy \\ Mosul University
}

(Received 22/9/2008; Accepted 30/3/2009)

\begin{abstract}
Effect of fatty acids such as Myristic and Palmatic acids, on the rheological properties of sago starch during heating and cooling were studied using a dynamic rheometer, Haake Rotovisco RT20. Fatty acids were applied at $0.5 \%$ and $0.1 \%$ levels on the starch weight basis $(20 \% \mathrm{w} / \mathrm{w})$. The gelatinization temperature ( $\mathrm{TG}^{\prime}$ ) of sago starch dispersion was determined at $68.4^{\circ} \mathrm{C}$. The addition of both fatty acids inhibited the swelling of the starch and then caused an increase in TG' compared to the native starch. The storage modulus $\left(\mathrm{G}^{\prime}\right)$ increased to a maximum value and dropped during heating of the starch. The reduction of peak $\mathrm{G}^{\prime}$ value was $737900 \mathrm{~Pa}$. The extent of breakdown in $\mathrm{G}^{\prime}$ during heating was high without addition of fatty acids. Hence the $G^{\prime}$ values of sago starch increased on cooling as well with the addition of fatty acids. The peak loss tangent $(\tan \delta)$ reached a maximum value at 2.728 and then dropped on heating. In contrast, during cooling the loss tangent values decreased. Swelling behaviour of sago starch granules with and without fatty acids was studied. As a result, the addition of Myristic acid to the sago starch decreased the swelling power values (SP) rather than the Palmatic acid .
\end{abstract}

Key words: Sago starch, fatty acids, rheological behaivour, swelling power.

\section{درلسة تأثير إضلفة الكماض الهنية (المايوستيك والبالمتيك) عل الهفلت الريولوجية

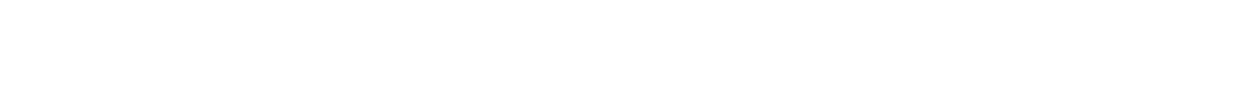

\section{المالغ}

يتضمن البهث درلسة تأثير الأحماض الدهنية مل المايوستيك والبالمتيك على الصفلت الريولوجية التي تؤثر على نمطسريلن المائع عند تسليط قوة خلل التسخين والتبريد بلستخدلم جهاز ( dynamic rheometer (Haake Rotovisco RT20 وفي هذه الدرلسة تمت إضلفة الأحماض الدهنية أعلاه بترلكيز 0.1\% و بالنبة إلى وزن النشأ. وقد لوهظ لن درجة حرارة تحول النشأ إلى جيلاتين (TG') كانت 
أن إضفافة هنين الحلمضين الدهنين قللت من انفاخ النشأ في المحلول وزياة قيم ('TG) مقارنة بمحلول النشأ

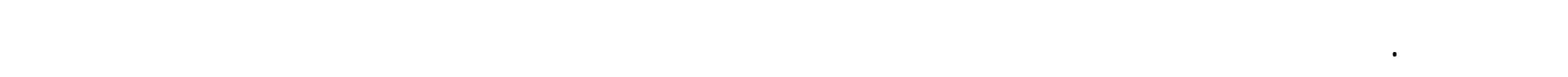

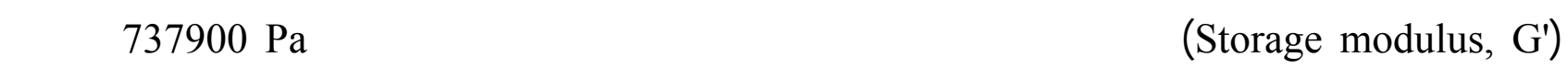

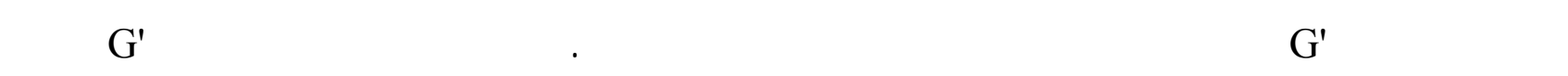

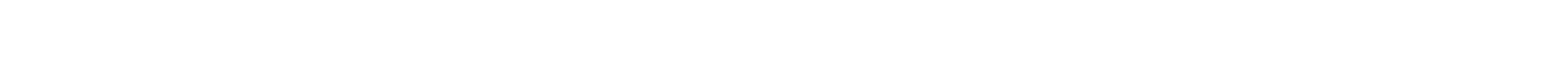

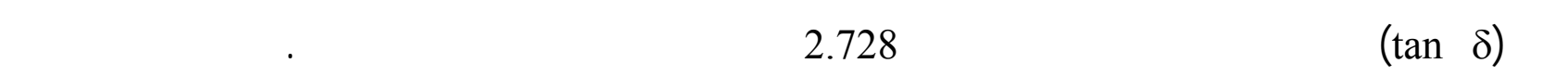

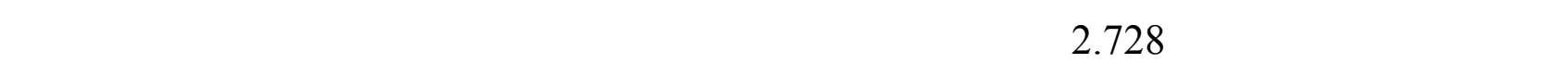

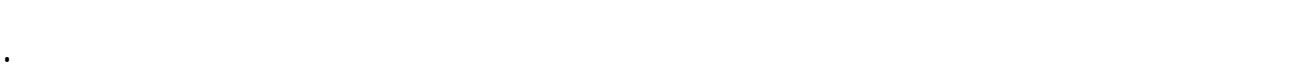

\section{INTRODUCTION}

Starch and its derivatives may have a wide range of applications in the manufacture of foods, paper, textiles, adhesives, pharmaceuticals and building materials. By treatment of starch, granular-modified starches with a different desirable physical properties may be produced (Roel,1985). When an aqueous suspension of starch is heated, water molecules around the granule disrupt the hydrogen bonding and enter the granules which then swell. This swelling and absorption of water are an irreversible process, termed gelatinization. This process leads to the preparation of viscous suspension and this determines the temperatures at which a starch paste takes on the desired processing qualities. Sago starch consists of linear chain polymer of amylase, branched polymer termed amylopectin and contains a very small percentage of fatty acids (about $0.1 \% \mathrm{w} / \mathrm{w}$ ) compared to corn, wheat, and rice starches. The presence of lipids in starch has a great effect on the physical properties of starch. The lipids exist as an amylase-lipid inclusion complex in the granules. These complexes are insoluble but dissociate when heated in water above their gelatinization temperature (TG) and tend to restrain the swelling and solubilization of starch granules(Stylianos, 2008). The swelling power of starch denotes a maximum increase in volume and weight of starch which absorbed water. Thus, it is dependent upon the strength and nature of the associate forces within the network of starch granule. Factors affecting the associative forces include the amylase to amylopectin ratio, molecular weight of fraction, degree of branching, and the location of fatty acid on the homogenuous starch series ( Radley,1976). The measurement of rheological properties such as viscosity, storage modulus $\left(\mathrm{G}^{\prime}\right)$ and loss tangent ( $\tan \delta$ ), in addition to swelling power (SP), can help to develop a better product during and after processing and predict its end use performance with customers ( Tako, 2002). The rheological behaviour of gelatinization of sago starch dispersion at varies concentrations and temperature range studied by Nurul, 1999. Gels were usually classified into two major categories, the strong and the weak gels (Lapasin, 1995). Strong gels have the characteristics of true gels where under small deformation conditions, they manifest typical behavior of viscoelastic solids and, above a critical deformation value, they rupture rather than flow. Weak gels, on the other hand, possess intermediate rheological properties between solutions and strong gels. Under small deformation, weak 
gels resemble strong gels in their mechanical behavior, but as deformation increases, the three-dimensional networks undergo a progressive breakdown into smaller clusters (Rosalina, 2002). Extent of breakdown in $\mathrm{G}^{\prime}$ is a study of the rigidity of the starch. From the previous study, the extent of breakdown in $\mathrm{G}^{\prime}$ during heating was higher for potato starch than for corn starch which confirmed the more rigid structure of corn starch granule. During cooling, the $G^{\prime}$ values increased and $\tan \delta$ values decreased with decrease in temperature and with and without the addition of fatty acids (Singh, 2001).Starch granules are insoluble in cold water due to the hydrogen bonds, formed either directly via neighboring alcoholic $\mathrm{OH}$ groups of the individual starch molecules or indirectly via water bridges. The hydrogen bonding forces are weak, but there are so many hydrogen bonds in a starch granule that it does not dissolve in cold water. Starch granules swell slightly in cold water, about $10-15 \%$ increase in diameter, but this swelling is reversible. The granules shrink back to their original dimensions on drying.

\section{Material}

\section{MATERIALS AND METHODS}

Sago starch was purchased from sago factory in Sarawak, Malaysia. Myristic acid or tetradecanoic acid ( melting point $53.9^{\circ} \mathrm{C}$ ) and Palmatic acid or hexadecanoic acid ( melting point $63.1^{\circ} \mathrm{C}$ ) were supplied from Sigma-Aldrich company.

\section{Rheological measurements:}

Rheological measurement were carried out using a dynamic rheometer, Haake Rotovisco RT 20 with a concentric cylinder measuring geometry. The oscillation frequency was fixed at $1 \mathrm{~Hz}$. and the rheological parameter of sago starch without and with fatty acids as 0.5 and $1.0 \%$ ( on the basis level of starch) were measured at constant strain of 0.005 and the duration is $120 \mathrm{~min}$. for each heating ( 20 to $85^{\circ} \mathrm{C}$ ) and cooling ( 85 to $5^{\circ} \mathrm{C}$ ) processes.

\section{Swelling power:}

Samples of starch dispersion ( Li,2001) for each level of fatty acid addition and without this addition were heated at $85^{\circ} \mathrm{C}$ in a shaking water bath for an hour followed by rapid cooling to room temperature. The dispersion then centrifuged at $5000 \mathrm{rpm}$ for 20 minutes. The supernatant was poured out from the centrifugal tube then dried in oven at $100^{\circ} \mathrm{C}$. This procedure repeated for three trials of each starch dispersion samples. Then the SP and water soluble index (WSI) were calculated as shown in the results.

\section{Rheological Measurements:}

\section{RESULUTS AND DISCUSSION}

The dynamic rheological properties, storage modulus $\left(\mathrm{G}^{\prime}\right)$ and loss tangent $(\tan \delta)$, were determined. The $\mathrm{G}^{\prime}$ of sago starch progressively increased to a maximum value and then dropped during heating ( Figure 1) .

At an early stage the increase in $\mathrm{G}^{\prime}$ was relatively small. This indicated that amylose molecules were dissolved from the swollen starch particles. With the increase in temperature, the $\mathrm{G}^{\prime}$ increased and reached to a maximum value which may be attributed to the closely packed network of swollen starch granules. 
With further increase in temperature, $\mathrm{G}^{\prime}$ decreased indicating that the gel structure was destroyed during prolonged heating. This destruction was probably in accordance with the melting of the crystalline region remaining in the swollen starch granules. The melting of the crystalline region deformed and loosened the particles.

Figure 2 shows the effect of cooling on sago starch without the addition of fatty acids.

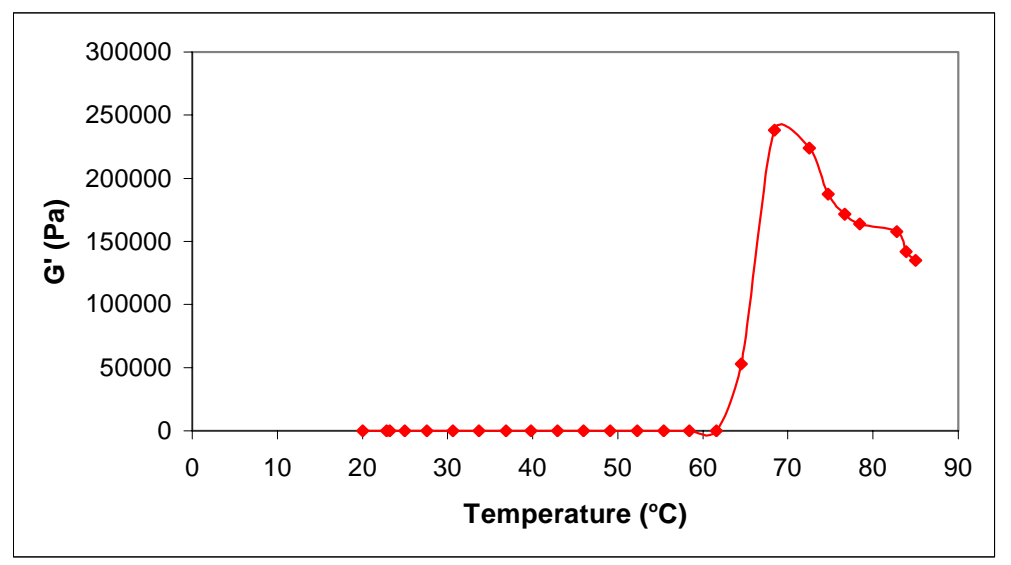

Fig.1: Effect of heating $20-85^{\circ} \mathrm{C}$ on the storage modulus (G') of sago starch

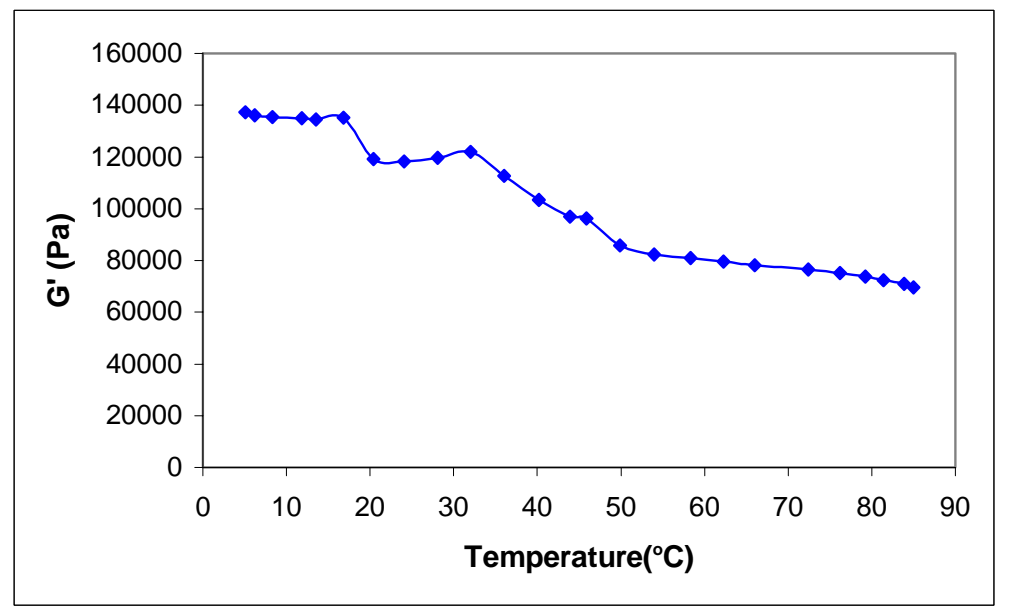

Fig.2: $\quad$ Effect of cooling on the storage modulus (G') of sago starch $\left(85-5^{\circ} \mathrm{C}\right)$ 


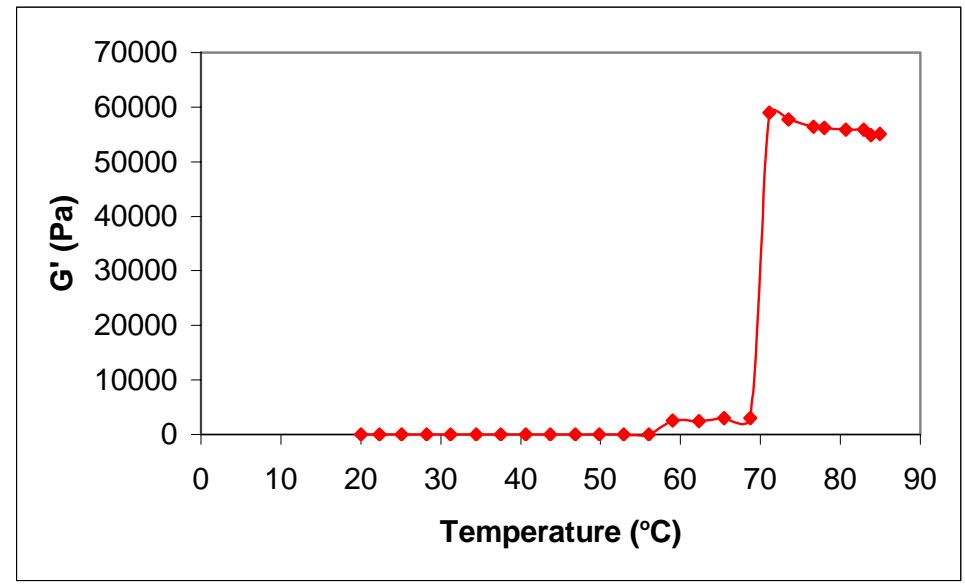

Fig.3: Effect of heating $\left(85-5^{\circ} \mathrm{C}\right)$ on the storage modulus $\left(\mathrm{G}^{\prime}\right)$ of sago starch in the presence of $0.5 \%$ myristic acid

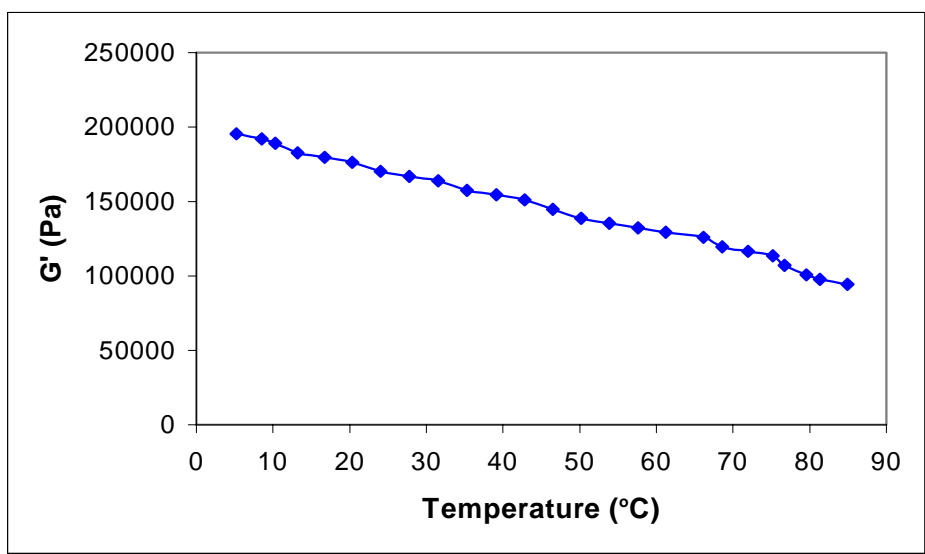

Fig .4: Effect of cooling on the storage modulus $\left(\mathrm{G}^{\prime}\right)$ of sago starch in the presence of $0.5 \%$ myristic acid $\left(85-5^{\circ} \mathrm{C}\right)$

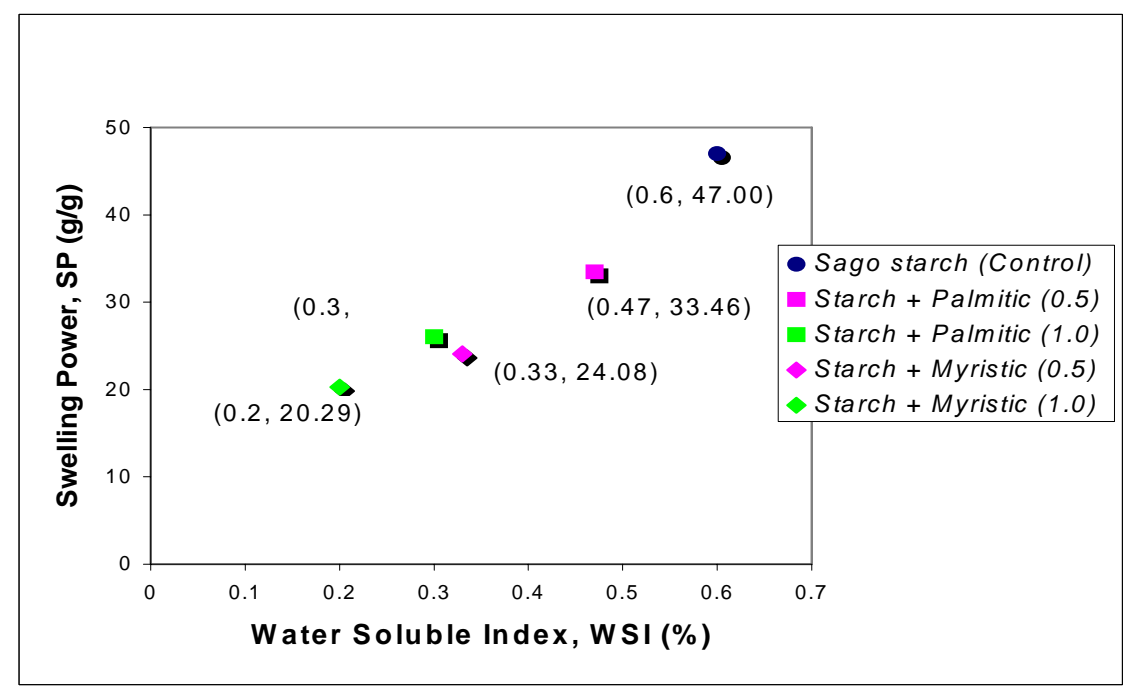

Fig. 5: The correlation between swelling power and water soluble index 
Table 1 and Table 2 show the results of the rheological properties of sago starch without and with fatty acids during heating and cooling. Sago starch showed a gelatinization temperature $\left(\mathrm{TG}^{\prime}\right)$ of $68.4^{\circ} \mathrm{C}$. This result is in agreement to $70^{\circ} \mathrm{C}$, as reported in previous study. Double helical and crystalline structures are disrupted in starch during gelatinization (Singh, 2001). The peak $\mathrm{G}^{\prime}$ for native sago starch was $237900 \mathrm{~Pa}$ at the corresponding $\mathrm{TG}^{\prime}$. Addition of fatty acids increased the $\mathrm{TG}^{\prime}$ in sago starch.

Table 1: Rheological properties of sago starch with and without fatty acids during heating from $20-85^{\circ} \mathrm{C}$

\begin{tabular}{|c|c|c|c|c|}
\hline $\begin{array}{c}\text { Fatty acid levels } \\
(\mathbf{\%})\end{array}$ & $\mathbf{T G}^{\prime}\left({ }^{\circ} \mathbf{C}\right)$ & Peak $\mathbf{G}^{\prime}(\mathbf{P a})$ & $\begin{array}{c}\text { Breakdown in } \\
\mathbf{G}^{\prime}(\mathbf{P a})\end{array}$ & Peak tan $\boldsymbol{\delta}$ \\
\hline Sago starch & 68.4 & 237900 & 102800 & 2.728 \\
\hline $\begin{array}{c}\text { Myristic acid } \\
(0.5)\end{array}$ & 71.1 & 58950 & 3890 & - \\
\hline $\begin{array}{c}\text { Myristic acid } \\
(1.0)\end{array}$ & 71.8 & 35590 & 8690 & - \\
\hline $\begin{array}{c}\text { Palmitic acid } \\
(0.5)\end{array}$ & 72.3 & 61900 & 19370 & - \\
\hline $\begin{array}{c}\text { Palmitic acid } \\
(1.0)\end{array}$ & 73.0 & 59960 & 22500 & - \\
\hline
\end{tabular}

Table 2: Rheological properties of sago starch with and without fatty during cooling from $85-5{ }^{\circ} \mathrm{C}$.

\begin{tabular}{|c|c|c|}
\hline $\begin{array}{c}\text { Fatty acid levels } \\
(\mathbf{\%})\end{array}$ & Peak G' (Pa) & Peak tan $\delta$ \\
\hline Sago starch & 137300 & 0.070 \\
\hline $\begin{array}{c}\text { Myristic acid } \\
(0.5)\end{array}$ & 195400 & 0.123 \\
\hline $\begin{array}{c}\text { Myristic acid } \\
(1.0)\end{array}$ & 249400 & 0.129 \\
\hline $\begin{array}{c}\text { Palmitic acid } \\
(0.5)\end{array}$ & 282730 & 0.096 \\
\hline $\begin{array}{c}\text { Palmitic acid } \\
(1.0)\end{array}$ & 345800 & 0.109 \\
\hline
\end{tabular}


Both palmitic acid and myristic acid decreased the $\mathrm{G}^{\prime}$ of sago starch during heating. The $\mathrm{TG}^{\prime}$ of sago starch in the presence of palmitic acid (1\%) and myristic acid (1\%) were $73.0^{\circ} \mathrm{C}$ and $71.8^{\circ} \mathrm{C}$, respectively. There was not much difference in the value of $\mathrm{TG}^{\prime}$ between sago starch with and without fatty acids. It might be caused by the high $\mathrm{TG}^{\prime}$ of sago starch and its rigid starch granules.

The breakdown in $\mathrm{G}^{\prime}$ decreased in the presence of both palmitic acid and myristic acid. Sago starch without the addition of fatty acids showed a high breakdown value (102 800 $\mathrm{Pa}$ ). Starch heated with palmitic acid showed greater $\mathrm{G}^{\prime}$ breakdown values compared to those heated with myristic acid. This was probably due to the higher melting point of palmitic acid, which caused high disintegration of starch granules.

The $\mathrm{G}^{\prime}$ values of sago starch increased during cooling from $85^{\circ} \mathrm{C}$ to $5^{\circ} \mathrm{C}$. Addition of palmitic acid and myristic acid in sago starch resulted in an increase in $\mathrm{G}^{\prime}$ during cooling. The value of $\tan \delta$ in sago starch increased with the increase in temperature beyond TG'. The $\tan \delta$ value of sago starch was highest at $61.6^{\circ} \mathrm{C}$. All results including $\mathrm{G}^{\prime}$ and $\tan \delta$ are presented in Appendices A. Reddy and Seib (2000) reported that a decrease in $\tan \delta$ values during cooling of starches is the evidence of gel formation.

Figure 3 and 4 show the effect of heating and cooling on the $G^{\prime}$ of sago starch in the presence of $0.5 \%$ myristic acid, respectively.

The decrease in $\tan \delta$ might be caused by the retro gradation of leached out components and interaction of molecules remaining inside the granule reinforced the gel during cooling. A decrease in tan $\delta$ values with the addition of fatty acids in sago starch showed the formation of a rigid gel structure during the cooling process.

Tan $\delta$ for heating in the presence of fatty acids are not included in this report because the values are extremely far from what were expected. During heating, $\tan \delta$ indicates the rigidity and stability of starch granules at higher temperature. Although the results could not be obtained, the rigidity and stability of the granules can be shown by the result of $\mathrm{G}^{\prime}$. In the presence of fatty acids, $\mathrm{TG}^{\prime}$ of sago starch increased. This indicated the stability of the starch granules. The breakdown in $\mathrm{G}^{\prime}$ decreased with the addition of fatty acids. Lower disintegration of starch granules is the evidence of its rigidity.

\section{Swelling power}

Swelling behavior of sago starch granules in the presence of fatty acids (myristic and palmitic) has been studied. Starch gels are composites of swollen gelatinized granules embedded in a continuous amylose network. Swollen granules are mainly filled with amylopectin due to preferential leaching of amylose from the granules. Swelling power depends on several factors such as starch origin, concentration, amylose and amylopectin content, isolation procedure, thermal history, and nature of starch lipids (Navarro et al, 1996). The type and amount of amylose, the amylose/fatty acid ratio and the location of the fatty acid in the homologous series appear to influence the results obtained by fatty acids on the starch and those, which vary, from one system to another (Radley, $1976 \mathrm{~b}$ ).

Table 3 shows the swelling power values obtained at $85^{\circ} \mathrm{C}$ for sago starch granules with and without addition of fatty acids, for three trials of each sample. The water soluble index (WSI) and swelling power (SP) were calculated as follows (Li and Yeh, 2001):

$$
\begin{aligned}
& W S I=\left[W_{1} / 0.1\right] \times 1 \% \\
& S P=W_{S} /[0.1(1 \%-W S I)]
\end{aligned}
$$


where $\mathrm{W}_{1}$ is constant weight of supernatant after dried at $100^{\circ} \mathrm{C}$ and $\mathrm{W}_{\mathrm{S}}$ is the weight of the sediment. As a result in Table 4 and Figure 5, the suspension of sago starch showed a high value of SP . A trend of decreasing SP with addition of palmitic acid and myristic acid were observed due to amylase-lipid complex formation.

Table 3: Swelling power for sago starch with and without fatty acids

\begin{tabular}{|c|c|c|c|c|}
\hline & $\begin{array}{c}\text { Weight of } \\
\text { dried } \\
\text { supernatant, } \\
\mathbf{W}_{\mathbf{1}} \text { (g) }\end{array}$ & $\begin{array}{c}\text { Water Soluble } \\
\text { Index, WSI } \\
\mathbf{( \% )}\end{array}$ & $\begin{array}{c}\text { Weight of } \\
\text { sediment, W } \mathbf{S} \\
\mathbf{( g )}\end{array}$ & $\begin{array}{c}\text { Swelling } \\
\text { Power, SP } \\
\text { (g/g) }\end{array}$ \\
\hline $\begin{array}{c}\text { Sago } \\
\text { Starch }\end{array}$ & 0.06 & 0.60 & 1.88 & $47.00 \pm 0.61$ \\
\hline $\begin{array}{c}\text { Starch+ } \\
\text { Myristic } \\
(0.5 \%)\end{array}$ & 0.03 & 0.33 & 1.66 & $24.08 \pm 0.87$ \\
\hline $\begin{array}{c}\text { Starch+ } \\
\text { Myristic } \\
(1.0 \%)\end{array}$ & 0.02 & 0.20 & 1.62 & $20.29 \pm 1.66$ \\
\hline $\begin{array}{c}\text { Starch }+ \\
\text { Palmitic } \\
(0.5 \%)\end{array}$ & 0.05 & 0.47 & 1.72 & $33.46 \pm 0.65$ \\
\hline $\begin{array}{c}\text { Starch+ } \\
\text { Palmitic } \\
(1.0 \%)\end{array}$ & 0.03 & 0.30 & 1.82 & $26.05 \pm 0.91$ \\
\hline
\end{tabular}

The number of carbon atoms in myristic acid and palmitic acid are 14 and 16, respectively. Stearic acid with carbon number 18 was proven to show the greatest effect in increasing the gelatinization temperature (Singh et al., 2002), and consequently prolong the time for swelling of starch. That means, fatty acids with higher number of carbon atoms are supposed to have lower swelling power.

Swelling apparently is a property of amylopectin. High proportions of long chain molecules in amylopectin contributed to the increase in swelling (Sasaki and Matsuki, 1998). Cross-linking enhances molecular interactions by covalent bonding and reduces the swelling volume of the starch. Monoglycerides or fatty acids inhibited the extent of swelling. The swelling of starch granules is related to pasting behavior and rheological properties.

\section{CONCLUSION}

As a conclusion of this study, sago starch showed a high $\mathrm{TG}^{\prime}$, which is $68.4{ }^{\circ} \mathrm{C}$. The addition of both palmatic acid and myristic acid to sago starch were increased the $\mathrm{TG}^{\prime}$. Breakdown in the structure $\mathrm{G}^{\prime}$ increased to a maximum value and then dropped during 
heating of the sago starch. The peak of $G^{\prime}$ decreased in the presence of both fatty acids. On cooling, the $G^{\prime}$ values of sago starch increased and tan $\delta$ values decreased in decreasing the temperature with and without the addition of fatty acids. Nevertheless the swelling power of sago starch inhibited by adding myristic acid rather than palmitic acid.

\section{REFERENCES}

Li, J.Y. and Yeh A.I., 2001. Relationship Between Thermal, Rheological Characteristics and Swelling Power for Various Starches. J. of Food Engineering. 50: pp.141-148.

Lapasin, R. and Priel, S., 1995. Rheology of Industrial Polysaccharides Theory and Application . London: Blackie. 138 p.

Nurul, I.M., Azemi, B.M. and Manan, D.M.A., 1999. Rheological Behavior of Metroxylan Sagu Starch Paste. Food Chemistry, 64: pp.501-505.

Radley, J.A., 1976 a. Industrial Uses of Starch and its Derivatives. Applied Science Publisher Ltd. $422 \mathrm{p}$.

Radley, J.A., 1976 b. Starch Production Technology, Applied Science Publishers Ltd. 145 p.

Reddy, I. and Seib, P.A., 2000. Modified Waxy Wheat Starch Compared to Modified Waxy Corn Starch. Journal of Cereal Science, 31: pp. 25-39.

Roels, J.A., and Van Beynum, G.M.A., 1985. Starch Conversion Technology. Marcel Dekker, Inc. 96 p.

Rosalina, I. and Bhattacharya, M., 2002. Dynamic Rheological Measurements and Analysis of Starch Gels. Carbohydrate Polymers, 48: pp.191-202.

Singh, J. and Singh, N., 2001. Studies on the Morphological, Thermal and Rheological Properties of Starch Separated from some Indian Potato Cultivars. Food chemistry, 75: pp.67-77.

Stylianos, N. Raphaelides and Nikolas, G., 2008. Effect of Fatty Acid Addition on the Rheological Behavior of Amylomaize Starch Dispersion During Heating. Food Research International 41: pp. 75-88.

Tako, M. and Hizukuri, S., 2002. Gelatinization Mechanism of Potato Starch. Carbohydrate Polymers, 48: pp. 397-401.

Whistler, R.L. and Paschall, E.F., 1984. Starch: Chemistry and Technology. Academic Press, Inc. 